\title{
Patients Satisfaction about Magnetic Resonance Imaging Services at Combined Military Hospital, Dhaka
}

Rahman $\mathrm{MR}^{1}$, Munir $\mathrm{UR}^{2}$, Zafreen $\mathrm{F}^{3}$, Wahab $\mathrm{MA}^{4}$

DOI: https://doi.org/10.3329/jafmc.v15i1.48645

\begin{abstract}
Introduction: MRI investigation indicates sensitivity as well as specificity. The increasing clinical utility, coupled with the greater availability and capacity to perาform, has resulted in a dramatic increase in their use over the past de $\urcorner$ cades. The expectation of the care seekers has also increased and it is a major concern whether this increase in MRI result has improved patient outcomes or not.
\end{abstract}

Objective: The study was carried out with the aim to evaluate various aspects of satisfaction among the MRI performing patients at Combined Military Hospital, Dhaka.

Materials and Methods: This descriptive cross sectional study was carried out on patient satisfaction of MRI services at $\mathrm{CMH}$, Dhaka. A total of 186 patients performing investigation at MRI Department of CMH Dhaka since 01st May 2011 to 15th May 2011 were interviewed. Data were collected and analysed by face-to-face interview and reviewing medical record with the help of a questionnaire and checklist.

Results: The waiting time of 8-12 weeks for MRI was maximum among $24.7 \%$ patients; followed by $17.7 \%$ for $2-4$ weeks and $16.1 \%$ for 1-2 weeks. It also revealed that waiting time was higher (8-12 weeks) in Neurosurgery referred cases (33.3\%), Orthopaedic $(28.2 \%)$ followed by Neurology $(14.3 \%)(p<0.05)$. The outdoor patients experienced more waiting time in comparison to indoor patients. Orthopaedic referred cases had the highest $(53.8 \%)$ positive finding followed by Neurosurgery (15.1\%) and Medicine (7.5\%). A significant majority of the patients are satisfied $(68.81 \%)$ or very satisfied $(25.80 \%)$ with the MRI service.

Conclusion: This study finding will help the hospital administrator not only in monitoring the investigation but also to take measures to improve the facilities of MRI department.

Key-words: Magnetic Resonance Imaging, Combined Military Hospital, Patient Satisfaction.

\section{Introduction}

MRI investigation indicates sensitivity as well as specificity. The increasing clinical utility of new radiologic studies such as CT and MRI, coupled with the greateravailability and capacity to perform, has resulted in a dramatic increase in their use over the past several decades. There are concerns that the in appropriate use of imaging may contribute to rising health care costs. The first step in addressing issues of potential overutilization and inappropriate imaging practices is to perform observational studies of imaging use ${ }^{1}$. With the Improvement of socioeconomic conditions health awareness among people is on the increase leading to an ever increasing trend in the utilization of hospital services by the people in the community. The expectation of the care seekershas increased and they have started questioning the adequacy of patient care not only for quantity of service rendered but also the quality that is provided by the hospitals ${ }^{2}$.

In just a few decades, the use of magnetic resonance imaging (MRI) scanners has grown tremendously. Doctors may order MRI scans to help diagnose multiple sclerosis, brain tumours, torn ligaments, tendonitis, cancer and strokes, to name just a few. An $\mathrm{MRI}$ scan is the best way to see inside the human body without cutting it open.Multiple reasons are suggested that may increase utilization which includes perceived need for diagnostic certainty, as well as medico-legal and patient-driven factors ${ }^{3}$. Whether this increase in MRI utilization resulted in improved patient outcomes or not is a major concern now a day ${ }^{4}$.

The relatively recent introduction of MRI offers an opportunity to study the evolution of this new technology's use over time. The latest example of such new technology, MRI has one of the highest capital costs. Despite the cost, MRI has been hailed as the most exciting event in medical imaging since the introduction of radiographs, and called the diagnostic indicator par excellence for stationary, soft tissue ${ }^{5}$.The benefit of an MRI compared to an X-ray is that it is much more detailed, it can view more than just bones and joints, and it can produce 3-D images allowing the body to be viewed from many angles ${ }^{6}$.

Better medical and surgical care depends on availability of prompt and skilful diagnostic services. Among many modern diagnostic techniques MRI examination contribute to facilitating effective medication and treatment. Diagnostic MRI plays a vital role in diagnosis of Disease. It improves the quality and efficiency of health care. It can provide support to the doctors when the disease is difficult to diagnose clinically ${ }^{7}$. The present study aimed at assessing the level of satisfaction of the MRI performing patients at $\mathrm{CMH}$ Dhaka in terms of waiting time in different specialty, incurred cost and along with an overall level of satisfaction.

\section{Material and Methods}

This descriptive cross sectional study was carried out with the aim to explore satisfaction among the MRI performing patients at Combined Military Hospital, Dhaka. A total of 186 patients accomplishing investigation at MRI Department of CMH Dhaka since 1st May 2011 to 15 th May 2011 were interviewed. Data

1. Col Md Rezaur Rahman, MBBS, MPH, Assistant Director of Medical Services (ADMS), 9 Infantry Division, Savar (E-mail: rahmanreza855@yahoo.com) 2. Col Umar Rashed Munir, MBBS, MPH, MBA (HRM), MPhil (PSM), ADMS, 17 Infantry Division, Sylhet 3. Dr Farzana Zafreen, MBBS, MPH, Associate Professor and Head, Department of Community Medicine, Medical College for Women \& Hospital, Uttara, Dhaka. 4. Lt Col Md Abdul Wahab, MBBS, MD, Associate Professor of Biochemistry, Armed Forces Medical College, Dhaka. 
were collected by face-to-face interview and reviewing medical record with the help of a questionnaire and checklist which included waiting time of the patients for MRI referred from different specialty, source of patient, expended cost and overall level of satisfaction incurred performing MRI. Data obtained was entered to SPSS-16 version. Univariate and bivariate analysis was carried out using descriptive statistics. Confidentiality about the participants was strictly maintained.

\section{Results}

Waiting time for MRI was maximum $(24.7 \%)$ for 8-12 weeks; followed by $(17.7 \%)$ for $2-4$ weeks and $(16.1 \%)$ for $1-2$ weeks. It also revealed that waiting time was higher (8-12 weeks) in Neurosurgery referred cases (33.3\%), Orthopaedic $(28.2 \%)$ followed by Neurology (14.3\%) and the waiting time difference among the departments was statistically significant $(p<0.05)$ (Table-I). Outdoor patients experience more waiting time (8-12 weeks) $(42 / 117$ i.e. $35.9 \%)$ in comparison to indoor patients (within 2 weeks) (42/69 i.e. 60.8\%)(Figure-1).Among the respondents $86.6 \%$ were entitled patients; rest $13.4 \%$ who were actually non-entitled patients opined that MRI cost at $\mathrm{CMH}$, Dhaka is cheaper than any government, semi-government or private hospital (Table-II).Orthopaedic referred cases had the highest $(53.8 \%)$ positive finding followed by Neurosurgery $(15.1 \%)$ and Medicine (7.5\%) (Table-III). Significant majority of the patients (both entitled and non-entitled) are satisfied $(68.81 \%)$ and very satisfied $(25.80 \%)$ with the MRI service. On the contrary a few $(5.37 \%)$ were either dissatisfied or very dissatisfied (Table-IV).

Table-I: Distribution of MRI waiting time by department $(n=186)$

\begin{tabular}{|c|c|c|c|c|c|c|c|c|c|}
\hline \multirow{2}{*}{ Department } & \multicolumn{7}{|c|}{ Patients waiting time in week } & \multirow{2}{*}{ Total } & \multirow{2}{*}{ Statistics } \\
\hline & $<1$ & $1-2$ & $2-4$ & $4-6$ & $6-8$ & $8-12$ & $>12$ & & \\
\hline Medicine & $\begin{array}{c}5 \\
(25.0)\end{array}$ & $\begin{array}{c}4 \\
(20.0)\end{array}$ & $\begin{array}{c}3 \\
(15.0)\end{array}$ & $\begin{array}{c}3 \\
(15.0)\end{array}$ & $\begin{array}{c}3 \\
(15.0)\end{array}$ & $\begin{array}{c}1 \\
(5.0)\end{array}$ & $\begin{array}{c}1 \\
(5.0)\end{array}$ & $\begin{array}{c}20 \\
(100)\end{array}$ & \multirow{6}{*}{$\begin{aligned} x^{2} & =38.40 \\
d f & =24 ; \\
p & <0.05\end{aligned}$} \\
\hline Orthopaedic & $\begin{array}{c}11 \\
(9.4)\end{array}$ & $\begin{array}{c}18 \\
(15.4)\end{array}$ & $\begin{array}{c}20 \\
(17.1)\end{array}$ & $\begin{array}{c}11 \\
(9.4)\end{array}$ & $\begin{array}{c}11 \\
(9.4)\end{array}$ & $\begin{array}{c}33 \\
(28.2) \\
\end{array}$ & $\begin{array}{c}13 \\
(11.1)\end{array}$ & $\begin{array}{c}117 \\
(100)\end{array}$ & \\
\hline Neurology & $\begin{array}{c}07 \\
(50.0)\end{array}$ & $\begin{array}{c}02 \\
(14.3)\end{array}$ & $\begin{array}{c}03 \\
(21.4)\end{array}$ & $\begin{array}{c}00 \\
(00)\end{array}$ & $\begin{array}{c}00 \\
(00)\end{array}$ & $\begin{array}{c}02 \\
(14.3)\end{array}$ & $\begin{array}{c}00 \\
(00)\end{array}$ & $\begin{array}{c}14 \\
(100)\end{array}$ & \\
\hline Neurosurgery & $\begin{array}{c}02 \\
(6.7) \\
\end{array}$ & $\begin{array}{c}06 \\
(20.0) \\
\end{array}$ & $\begin{array}{c}05 \\
(16.7) \\
\end{array}$ & $\begin{array}{c}04 \\
(13.3) \\
\end{array}$ & $\begin{array}{c}02 \\
(6.7) \\
\end{array}$ & $\begin{array}{c}10 \\
(33.3) \\
\end{array}$ & $\begin{array}{c}01 \\
(3.3) \\
\end{array}$ & $\begin{array}{c}30 \\
(100) \\
\end{array}$ & \\
\hline Others & $\begin{array}{c}02 \\
(40.0)\end{array}$ & $\begin{array}{c}0 \\
(00)\end{array}$ & $\begin{array}{c}02 \\
(40.0)\end{array}$ & $\begin{array}{c}00 \\
(00)\end{array}$ & $\begin{array}{c}01 \\
(20.0)\end{array}$ & $\begin{array}{c}00 \\
(00)\end{array}$ & $\begin{array}{c}00 \\
(00)\end{array}$ & $\begin{array}{c}05 \\
(100)\end{array}$ & \\
\hline Total & $\begin{array}{c}27 \\
(14.5) \\
\end{array}$ & $\begin{array}{c}30 \\
(16.1)\end{array}$ & $\begin{array}{c}33 \\
(17.7)\end{array}$ & $\begin{array}{c}18 \\
(9.7)\end{array}$ & $\begin{array}{c}17 \\
(9.1)\end{array}$ & $\begin{array}{c}46 \\
(24.7) \\
\end{array}$ & $\begin{array}{c}15 \\
(8.1) \\
\end{array}$ & $\begin{array}{c}186 \\
(100)\end{array}$ & \\
\hline
\end{tabular}

* Percentage in parenthesis

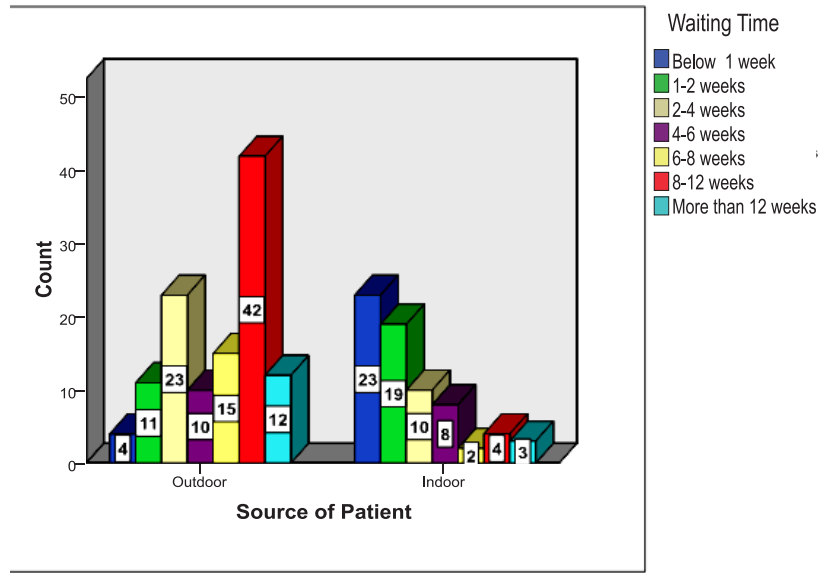

Figure-1: Distribution of MRI by waiting time and source of patient
Table-Il: Distribution of patients as per entitlement $(n=186)$

\begin{tabular}{|l|c|c|}
\hline \multicolumn{1}{|c|}{ Entitlement } & Frequency & Percentage \\
\hline Entitled & 161 & 86.6 \\
\hline Non-entitled & 25 & 13.4 \\
\hline Total & 186 & 100 \\
\hline
\end{tabular}

Table-III: Distribution of MRI finding according to department $(n=186)$

\begin{tabular}{|l|c|c|c|}
\hline \multirow{2}{*}{ Department } & \multicolumn{2}{|c|}{ Finding of Patients } & \multirow{2}{*}{ Total } \\
\cline { 2 - 3 } & Positive & Negative & \\
\hline \multirow{2}{*}{ Medicine } & 14 & 06 & 20 \\
& $(7.5)$ & $(3.2)$ & $(10.8)$ \\
\hline \multirow{2}{*}{ Orthopaedics } & 100 & 17 & 117 \\
& $(53.8)$ & $(9.1)$ & $(62.9)$ \\
\hline \multirow{2}{*}{ Neurology } & 10 & 04 & 14 \\
& $(5.4)$ & $(2.2)$ & $(7.5)$ \\
\hline \multirow{2}{*}{ Neurosurgery } & 28 & 02 & 30 \\
& $(15.1)$ & $(1.1)$ & $(6.1)$ \\
\hline \multirow{2}{*}{ Others } & 05 & 00 & 05 \\
& $(2.7)$ & $(00)$ & $(2.7)$ \\
\hline \multirow{2}{*}{ Total } & 157 & 29 & 186 \\
& $(84.4)$ & $(15.6)$ & $(100)$ \\
\hline
\end{tabular}

* Percentage in parenthesis

Table-IV: Distribution of respondent's satisfaction in performing MRI $(n=186)$

\begin{tabular}{|l|c|c|c|c|c|}
\hline \multirow{3}{*}{ Type of patient } & \multicolumn{4}{|c|}{ Patients satisfaction status } & \multirow{2}{*}{ Total } \\
\cline { 2 - 5 } & $\begin{array}{c}\text { Very } \\
\text { satisfied }\end{array}$ & Satisfied & Dissatisfied & $\begin{array}{c}\text { Very } \\
\text { dissatisfied }\end{array}$ & \\
\hline \multirow{3}{*}{ Entitled } & 06 & 15 & 03 & 01 & 25 \\
\cline { 2 - 6 } & $(24.00)$ & $(60.00)$ & $(12.00)$ & $(04.00)$ & $(100)$ \\
\hline \multirow{2}{*}{ Non-entitled } & 42 & 113 & 05 & 01 & 161 \\
\cline { 2 - 6 } & $(26.08)$ & $(70.18)$ & $(03.10)$ & $(00.62)$ & $(100)$ \\
\hline \multirow{3}{*}{ Total } & 48 & 128 & 08 & 02 & 186 \\
\cline { 2 - 5 } & $(25.80)$ & $(68.81)$ & $(4.30)$ & $(1.07)$ & $(100)$ \\
\hline
\end{tabular}

${ }^{*}$ Percentage in parenthesis

\section{Discussion}

The present study delineated that waiting time of 8-12 weeks for MRI was maximum among $24.7 \%$ patients; followed by $17.7 \%$ for 2-4 weeks and $16.1 \%$ for $1-2$ weeks. It also reveals that waiting time was higher (8-12 weeks) in Neurosurgery referred cases (33.3\%), Orthopaedic (28.2\%) followed by Neurology $(14.3 \%)$ $(p<0.05)$. The outdoor patients experienced more waiting time (8-12 weeks) (42/117 i.e. $35.9 \%$ ) in comparison to indoor patients (< 2 weeks) (42/69 i.e. 60.8\%).A summary was explored of current waiting time for accessing the two MRI services designed to serve residents of Waterloo Region, Wellington and Dufferin Counties $^{8}$. High need explains 01 week for inpatients; 1-2 weeks for outpatients e.g., spinal cord compression of cancer patient and acute stroke, acute onset of complex neurological symptoms. Medium need explained as 3-6 months e.g. gradual symptoms (not acute) but not going away. Low needof 3-6 monthsit is worth 
repeating that the waiting times for medium and low need patients will fluctuate on an ongoing basis, depending upon the number of high need patients that will receive priority. e.g., chronic symptoms, e.g., low back pain, hip and knee, headaches ${ }^{8}$.

Among the respondents $86.6 \%$ were entitled patients; rest $13.4 \%$ who were actually non-entitled patients; who opined that MRI cost at $\mathrm{CMH}$, Dhaka is comparatively cheaper than any government, semi-government or private hospital. Cost per MRI was evaluated in different government and private hospitals of Dhaka. Costs in different hospitals were found as follows DMCH Tk 3000.00, BSMMU Tk 5000.00, Private (Square Hospital) Tk 6000.00, CMH Dhaka Tk 5000.00. For most of the patients (86.6\%) who are entitled to get the treatment free, the question of cost was not applicable. In study of Inpatient Radiology utilization trends over the past decade by Gilk $\mathrm{T}$ et $\mathrm{al}^{9}$ it was found that the cost of an MRI study can range from $\$ 300$ to $\$ 10000$.

It was depicted that Orthopaedic referred cases had the highest $(53.8 \%)$ positive finding followed by Neurosurgery $(15.1 \%)$ and Medicine $(7.5 \%)$. A significant majority of the patients (both entitled and non-entitled) are satisfied (68.81\%) and very satisfied $(25.80 \%)$ with the MRI service. On the contrary a few $(5.37 \%)$ were either dissatisfied or very dissatisfied. A study by Kumar and Rao in Teaching Tertiary Care Hospital in Telangana revealed that overall $74.5 \%$ of the patients were satisfied with the waiting time, $80.5 \%, 77.5 \%$ and $86.5 \%$ of the patients were satisfied with guidance to reach MRI facility, staff behaviour and staff communication respectively. $85.5 \%$ opined that utilization of waiting time by providing information regarding MRI is useful, and $62 \%$ of them requested to have trained personnel by their side during the procedure ${ }^{10}$.

\section{Conclusion}

MRI services analysis is a fundamental management technique to point out the wastage of MRI service with a view to save huge amount of Government money and unnecessary exposure to MRI. This MRI services analysis will help the hospital administrator not only in monitoring the investigation but also to take measures to improve the facilities of MRI department.

\section{References}

1. Rankey D, Leach J, Leach S. Emergency MRI Utilization Trends at a Tertiary Care Academic Medical Center: Baseline Data 2008; 15(4):438-43.

2. Diagnostic Imaging Utilization Management.American Imaging Management, Inc. 2010.

3. Iron K R, Laupacis A. Evaluation of Health care Services. Institute for Clinical Evaluative Sciences (ICES). Ontario Ministry of Health and Longterm Care (MoHLTC) July 2003.

4. Borrett J, Martin S, Burkholder R et al. Waterloo Region Wellington Dufferin District Health Council Report 2004.

5. Baldor A R, Quirk M E, Dohan D. Magnetic Resonance Imaging Use by Primary Care Physicians. Journal of Family Physician 1993; 4:01-05.

6. Levine R. MRI Images and How They are made. The Image Bank. Doctors examine the contrasts on an MRI scan. Available from: URL: http:// howstuffworks.com/framed. htm?

7. Sharona V, Osnat L, Gabriel P, Miriam I S, Joshua S.CT and MRI Imaging in Israel -National Trends of Utilization. Harefuah 2003; 142(12): 810-4.

8. Smith L , Ruyle G, Maynard J et al. Principles of Obtaining and Interpreting Utilization Data on Southwest Rangelands 2006.

9. Gilk T, Bell B. Comfort Zone MRI Safety. Medical Imaging 2007; 14:08-14.

10. Kumar C N, Rao B R. Patient's Satisfaction with Diagnostic MRI Services in Teaching Tertiary Care Hospital in Telangana. International Archives of Integrated Medicine 2017; 4(1): 85-95. 